\title{
GCU
}

Glasgow Caledonian

University

University for the Common Good

\section{Process level environmental performance of electrodischarge machining of aluminium (3003) and steel (AISI P20)}

Gamage, Janaka R.; DeSilva, Anjali K.M.; Harrison, Colin S.; Harrison, David K.

Published in:

Journal of Cleaner Production

DOI:

10.1016/j.jclepro.2016.07.090

Publication date:

2016

Document Version

Author accepted manuscript

Link to publication in ResearchOnline

Citation for published version (Harvard):

Gamage, JR, DeSilva, AKM, Harrison, CS \& Harrison, DK 2016, 'Process level environmental performance of electrodischarge machining of aluminium (3003) and steel (AISI P20)', Journal of Cleaner Production, vol. 137, pp. 291-299. https://doi.org/10.1016/j.jclepro.2016.07.090

\section{General rights}

Copyright and moral rights for the publications made accessible in the public portal are retained by the authors and/or other copyright owners and it is a condition of accessing publications that users recognise and abide by the legal requirements associated with these rights.

Take down policy

If you believe that this document breaches copyright please view our takedown policy at https://edshare.gcu.ac.uk/id/eprint/5179 for details of how to contact us. 


\title{
Process level environmental performance of electrodischarge machining of aluminium (3003) and steel (AISI P20)
}

\author{
Janaka R. Gamage $^{\mathrm{a}}$, Anjali K.M. DeSilva*,a ${ }^{\text {, Colin S. Harrison }}{ }^{\mathrm{a}}$, David K. Harrison ${ }^{\mathrm{a}}$ \\ ${ }^{a}$ School of Engineering and Built Environment, Glasgow Caledonian University, Cowcaddens Road, Glasgow G4 OBA, United Kingdom \\ * Corresponding author. Tel.: +44-141-331-3522; fax: +44-141-331-3005. E-mail address: ade@gcu.ac.uk
}

\begin{abstract}
Electrodischarge machining (EDM) plays a significant role in the precision machining of super alloys and the die/mould manufacturing industry and hence warrants the study of its environmental impact and sustainability. However, process level data for unconventional machining practices are limited in the available Life Cycle Inventory (LCI) databases. This paper aims to accumulate process level LCI data for EDM and to assess the environmental impact using life cycle analysis. The method of assessment takes insights from ISO 14040 and the CO2PE initiative. Data from industrial case studies relating to diesinking EDM and wire EDM of steel and aluminium alloys are used. Environmental impact is calculated using the resultant LCI data and supplementary data from the Ecoinvent database. The ReCePi endpoint method is used in the impact assessment, enabling comparisons among environmental performances. Recommendations for improvements during the design phase of machine tools and the operational phase of the machines are given.
\end{abstract}

Key words: EDM; LCI; LCA; Environmental impact

\section{Introduction}

The increasingly stringent regulations on environmental impact which are now in place and the growing awareness of resource depletion are the main drivers for the surge of interest in sustainability research in almost every field of manufacturing. Optimisation of energy usage and the use of alternative modes of energy have gained considerable recent attention. Total world energy consumption by end-use sector including losses during 2011 was 524 quadrillion Btu, of which $51 \%$ was attributed to the industrial sector (USEIA, 2013). Concerning emissions, the manufacturing industry is responsible for a major share of environment pollution (Leão and Pashby, 2004; Tan et al., 2002). In 2011, greenhouse gas emissions in the European Union manufacturing sector amounted to 937 million tonnes of $\mathrm{CO}_{2}$ - equivalents, representing $20 \%$ of total emissions for the period (Eurostat, 2014), a figure which is $2 \%$ higher than the total for household emissions and twice as much as the total emissions from transport. The global interest in pollution prevention is motivating manufacturing industries to implement environmental friendly strategies (Fratila, 2013). Machining, being one of the most widely used manufacturing processes (Munoz and Sheng, 1995), contributes significantly to that pollution figure (Dahmus and Gutowski, 2004; Ginting et al., 2015).

Steel and aluminium are two dominant subsectors among the many contributors to energy use and carbon emissions (Gutowski et al., 2013). World crude steel production increased from 595 million tonnes in 1970 to 1,606 million tonnes in 2013, with a 2010-13 growth rate of 3.9 (World Steel Association, 2014). The growth in consumption alongside diminishing resources has led to research into more environmentally benign manufacturing, which includes life cycle thinking. Life cycle analyses (LCA) of products have become a common practice to assess the environmental footprint of products. Although LCA is popular at system level manufacturing, the focus on unit-based manufacturing at process level has been marginal (Gamage and DeSilva, 2015; Yeo et al., 1998). This is further confirmed by (Duflou et al., 2011), who stated that processes used for discrete part manufacturing have poor records in terms of their environmental footprint. As a solution, a worldwide consortium of universities and research institutes has developed the CO2PE! initiative (Cooperative Effort on Process Emissions in Manufacturing) (Kellens et al., 2011a). CO2PE! is a method designed to generate life cycle inventory (LCI) data for manufacturing processes. 
An extensive collection of LCI data for steel, aluminium and plastics is available in the International Iron and Steel Institute (IISI), the European Aluminium Association, and Plastics Europe, respectively. However, this data is typically focused on the primary production of the materials into the forms of sheets and foils (Kellens et al., 2011a). LCI data on manufacturing process levels has limited availability or is incomplete. The Ecoinvent database (Ecoinvent centre, 2015), one of the most widely referenced LCI databases, holds a vast range of LCI data. Despite the well-documented material production data, LCI data on manufacturing unit processes still leave room for significant improvement. The available data mostly cover conventional processes such as turning, milling and casting, whereas non-conventional processes, for example electro discharge machining, lack similar records (Duflou et al., 2012). Energy efficiency, which is a key contributor to environmental impact, has also been studied for conventional manufacturing unit processes, but data for non-conventional machining has scarcely been gathered. The EDM process is at least 1000 times more energy intensive than conventional material removal processes because the material removal rate (MRR) is much lower for EDM than it is in conventional machining ( $\mathrm{Li}$ and Kara, 2015).

This paper assesses the environmental performance of electrodischarge machining (EDM) unit processes. It gathers unit process LCI data, taking some insights from ISO 14040 and CO2PE! approaches (Section 2). Four case studies using tool steel (AISI P20) and aluminium alloy (3003 H12) are conducted with diesinking and wire EDM (see section 2.4). Studies are carried out in an industrial machining centre in consideration of the scale benefits of volume of production in terms of resource utilisation and emissions. Further, this paper provides a comparison of environmental impact of two metals, steel and aluminium, and highlights the differences in analysis of wire EDM and diesinking EDM (see section 3). The paper concludes by drawing attention to key contributors with high environmental impacts, and by suggesting further research directions.

\section{Research Approach}

The prior literature on environmental impact assessment and energy efficiency analysis methods were reviewed. Based on the methods identified, a pilot study was conducted at the laboratory level using a TOP EDM-spark erosion machine. The data collection framework was then developed, drawing insights from ISO 14040 and the CO2PE! method. A threefold study of energy, resources and emissions was then undertaken as illustrated in Figure 1. The objective was to capture the data required to estimate the environmental impact of a set period of machining.

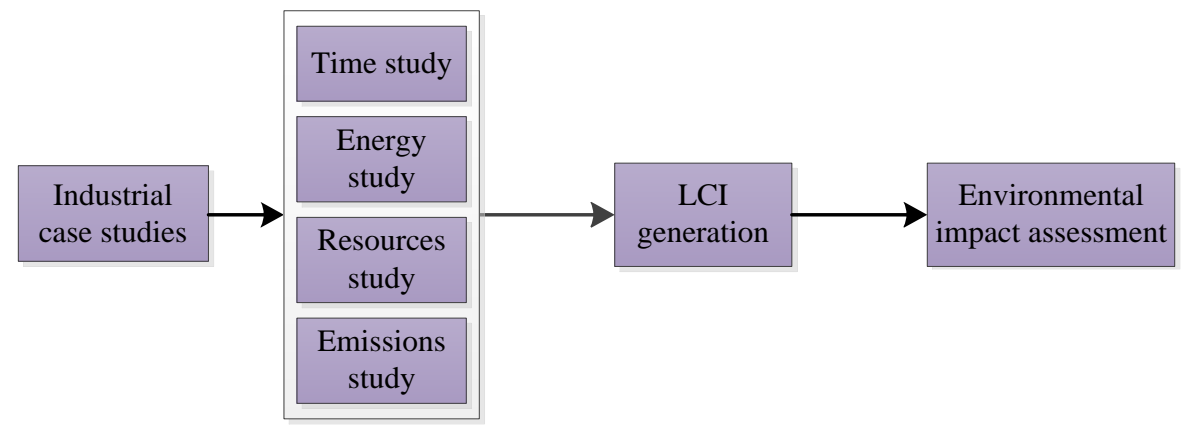

Figure 1: Overview of research approach

Case studies help to capture industry dynamics and economies of scale more effectively than a laboratory experiment in a controlled environment. For example, there are shared air compressors or extractors in machining centres while that may not be the case in a laboratory. As most of the LCI data are used to analyse and compare industry unit processes with each other, it is more appropriate to use industry data. The disadvantage of doing so is the difficulty or inability of controlling the parameters as can be done in a laboratory environment. 


\subsection{Goal and scope definition}

ISO 14044:2006 LCA requirements and guidelines (International Organisation for Standardisation, 2006) requires that the goal and scope of impact assessment are defined. This study aims to ascertain the LCI data of process level EDM and to perform a life cycle impact assessment for steel (AISI P20) and aluminium (3003). The production and after life treatments of the machines, equipment and consumables' packaging involved are excluded. However, both productive and non-productive but essential (such as setting-up and shutting down activities) production parameters are taken into account for impact assessment. Further, a life cycle assessment for a unit time of EDM for a given material with a given MRR is produced.

Then the functional unit for LCA is set. A functional unit is a measure of the function of the system analysed, which provides a reference to relate the inputs and outputs to, which will then make it easy to compare them with alternative products or processes. Given the nature of this study, setting a functional unit is complex, as the researcher has minimal control over operating parameters. However, a reference is defined as one hour of machining of a given material under given discharge current or MRR. The objective of the study is more focused on how to ascertain the LCI data of a machining process and to identify key contributors to the environmental impact. It excludes comparison of two machining methods, such as EDM and milling, to do the same machining task to a similar surface finish. Further, it excludes the impact of tool electrode preparation and workpiece preparation.

The EDM process is based on variety of parameters with complex influences on machining performance which thus have multifarious environment impacts. These include tool parameters (material, electrode shape, polarity, wear ratio, etc.), work parameters (material, melting point, conductivity, thermal properties, etc.), machining parameters (discharge current, on/off time, ram frequency, wire feed, etc), dielectric parameters (electrical resistivity, viscosity, specific heat capacity), and other parameters (Li and Kara, 2015; Maher et al., 2015). However, the methodology for data collection is from industry case studies which will provide access to resources and emissions data in industry scale rather than a laboratory scale. Furthermore, most industrial CNC EDM machines assign parameters automatically once the programme is selected based on the material and mode of cut. Therefore, industry case studies hardly permit control of parameters unless a manual override is necessary to get the required work done. As most of the design parameters for EDM are reflected in the MRR, the impacts are calculated for the given MRR for a unit time of machining.

\subsection{Time and Energy study}

The energy utilisation during conventional machining is largely dependent on the design parameters, such as, part geometry, material type, as well as set-up parameters like the cutting fluid selection (Munoz and Sheng, 1995). The same applies to unconventional machining and, thus, designing experiments to capture the energy data is important. The machine layout with the positioning of sub components, their communications with the main control and their interrelations are examined to comprehend energy utilisation.

The total energy consumption during machining is formulated from energy consuming sub units, for example pumps, coolers, servos, discharge generators, etc. Capturing information for each sub unit individually is essential for the empirical development of LCI data for the unit time of machining. The total energy consumption of the machine tool is monitored using 'Elcomponent's SPC®' current data logger (range: 2-200A, accuracy: $\pm 1 \%$ of measurement, sample rate: $1.6 \mathrm{kHz}$ ) attached to the main supply points. For capturing the energy consumption of sub units, a 'Fluke ${ }^{\circledR}$ - current clamp' (range: 0-40A, accuracy: $2 \% \pm 5$ digits, resolution: 0.1 A) was used and the nameplate data of each sub unit were recorded. It is common practice to use portable/mobile instruments with metering and logging functions in industry case studies (Kara et al., 2011). A time study is required to trace the detailed operation of sub units in order to calculate the energy consumption of each phase of machining.

The time study is designed to use video recording method, which is a widely used method to capture events (Maynard and Zandin, 2001) especially with a limited number of observers and in industry set-ups where the researchers have less/no control over the flow of operations. This method helps to identify various use modes 
during the full machining duration which makes it possible to account for their respective contribution to the total energy consumption, as is evident in many such studies (Devoldere et al., 2008; Duflou et al., 2011). Two cameras were used, one still and one mobile. The still camera was set to capture the full machine, including operator interactions. This arrangement helps to clearly identify the setup time, machining time, breakdown time and any standby times. The mobile camera is used as and when required to get a closer view of the machining operation and to record the operation of sub units while the machining continues.

\subsection{Resources and emissions study}

The resource study identifies the types and the amounts of resources consumed for each machining process. These include, for example, dielectric, deionising resins, filters, electrode wires, etc. However, accounting for direct resource consumption for given session of machining is a challenge as, for example, die electric is reused/recirculated and replaced based on the usage and type of machining. Thus, the replacement time period would differ from case to case. However, estimation can be made based on the replacement periods suggested for the proper maintenance of the machine.

The liquid and solid emissions or waste can be mapped with input resources and replacement frequencies. However, gaseous emissions, which are the most immediate occupational health hazards, are hard to capture. Most machine shops are equipped with common ventilation system. Nevertheless, particulate matter density in the close proximity of the machine may still rise above the permissible limits. Further, the actual hazardous potential is likely to differ based on the type of the metal being machined (Evertz et al., 2006), which makes it even more difficult to monitor. Typical emission testing methods for aliphatic compounds are infrared spectrometry (IR) and gas chromatography, followed by mass spectroscopy (GC-MS) for chemical analysis. Additionally, airborne emissions are tested for polycyclic aromatic hydrocarbons (PAH), any metal compounds based on work material are tested using atomic absorption spectrometry (AAS), and BTEX (benzene, toluene, ethylbenzene and xylene) compounds are tested using other sophisticated methods (Evertz et al., 2006; Sivapirakasam et al., 2011). All these methods require a dedicated enclosure covering the whole machine in order to capture the gaseous emissions with inlet and outlet air filters. Consideration in a past study of process emissions during EDM based on a working scheme of 2000 hours a year has resulted in almost zero environmental impact compared to other contributors (Kellens et al., 2011b). Having considered the significance of the impact from gaseous emissions as per previous studies and the practical difficulty of setting up a dedicated emission capturing apparatus in an industrial environment, gaseous emissions are excluded from the scope of this study. However, the significance of gaseous emissions at various levels of machining currents is discussed in the results section.

\subsection{Industry cases}

Observations are made with diesinking EDM (DSEDM) and wire EDM (WEDM) processes with machining jobs involving aluminium alloy (3003-H12) and steel (AISI P20) work pieces. A King EDM® CNC EDM NK series die sinker machine and a KingSpark® wire cut CNC EDM AL-5 series machine are studied. The chemical composition of aluminium alloy 3003 is presented in Table 1. The alloy has good weldability and corrosion resistance. Typical applications includes heat exchangers, evaporators, storage tanks and pipes for chemical and food products, cooking utensils, and bakery moulds. The alloy has a thermal conductivity of 190 $\mathrm{W} / \mathrm{mK}$ and an electrical resistivity of $0.034 \times 10^{-6} \Omega \mathrm{m}$ (Aalco, 2015). Tempering grades and properties for various grades of $\mathrm{Al}$ material at various thickness levels can be found in the American Society for Testing and Materials (ASTM) B209 standard (ASTM Standard B209, 2014).

Table 1: Chemical composition of Aluminium alloy EN AW-3003 - BS EN 573-3:2013 (British Standards Institution, 2013)

\begin{tabular}{llllllll}
\hline Element & $\mathrm{Si}$ & $\mathrm{Fe}$ & $\mathrm{Cu}$ & $\mathrm{Mn}$ & $\mathrm{Zn}$ & Others & $\mathrm{Al}$ \\
\hline Composition $(\%)$ & 0.6 & 0.7 & $0.05-0.20$ & $1.0-1.5$ & 0.10 & $0.0-0.15$ & Remainder \\
\hline
\end{tabular}

The low carbon steel AISI P20 (ASTM A681) is commonly used for low temperature applications including injection moulds and dies for die castings. It is one of the most common material types processed by the centre 
as it is mainly involved in die and mould production. The metal has a density of $7.85 \mathrm{~g} / \mathrm{cm}^{3}$, and a thermal conductivity of 29-34 W/m.K (Matweb, 2015). A typical chemical composition of AISI P20 steel is presented in Table 2.

Table 2: Chemical composition of AISI P20 steel

\begin{tabular}{lllllllll}
\hline Element & $\mathrm{C}$ & $\mathrm{Mn}$ & $\mathrm{Si}$ & $\mathrm{Cr}$ & $\mathrm{Mo}$ & $\mathrm{P}$ & $\mathrm{S}$ & $\mathrm{Fe}$ \\
\hline Composition (\%) & $0.28-0.40$ & $0.60-1.00$ & $0.20-0.80$ & $1.40-2.00$ & $0.30-0.55$ & $\leq 0.03$ & $\leq 0.03$ & Remainder \\
\hline
\end{tabular}

The details of machining configurations for each case, I and II, are listed in Table 3.

Table 3: Machining parameters for DSEDM cases

\begin{tabular}{lll}
\hline \multirow{2}{*}{ Description } & Case I & Case II \\
& DSEDM-Al & DSEDM-Steel \\
\hline Work specification & Aluminium alloy (3003) & Mould steel (AISI P20) \\
Tool Specification & Copper $(+)$ & Copper $(+)$ \\
& Contact area of $34.5 \mathrm{~cm}^{2}$ & Contact area of $8.5 \mathrm{~cm}^{2}$ \\
Peak discharge current $(\mathrm{A})$ & 6 & 6 \\
Open Voltage $(\mathrm{V})$ & 120 & 120 \\
Pulse ON time $(\mu \mathrm{s})$ & 175 & 175 \\
Pulse OFF time $(\mu \mathrm{s})$ & 40 & 40 \\
\hline
\end{tabular}

The details of machining parameters for the wire EDM cases (cases III and IV) are presented in Table 4.

Table 4: Machining parameters for WEDM cases

\begin{tabular}{lll}
\hline \multirow{2}{*}{ Description } & Case III & Case IV \\
& WEDM-Al & WEDM-Steel \\
\hline Work specification & Aluminium alloy (3003) & Mould steel (AISI P20) \\
Tool Specification & 6 mm thick plate & $11 \mathrm{~mm}$ thick plate \\
& Brass wire & Brass wire \\
Open voltage & $\emptyset 0.20 \mathrm{~mm}$ & $\emptyset 0.20 \mathrm{~mm}$ \\
Pulse ON time $(\mu \mathrm{s})$ & 9 & 8 \\
Pulse OFF time $(\mu \mathrm{s})$ & 5 & 8 \\
Wire feed $(\mathrm{m} / \mathrm{min})$ & 14 & 13 \\
Wire tension $(\mathrm{g})$ & 5 & 5 \\
\hline
\end{tabular}

\section{Results and discussion}

The results are presented separately for each type of study, with a discussion of their findings. Then the environmental impact assessment for each case followed by a sensitivity analysis is presented.

\subsection{Time studies}

The time taken during a machining job can be broadly categorised into productive time and non-productive time. Productive time is the time taken for tasks which directly add value to the material removal process. For EDM, this is the time taken for the discharging process. Non-productive time is the time taken for tasks which add no direct value to the workpiece being machined. These include machine set-up time (programme selection, work clamping, tool aligning, tank filling, etc.), standby/waiting time for operator intervention, wire rethreading time in the event of breaking, and finishing-up time (work and tool unclamping, cleaning, etc.). The video method enables the capture of time values for all these sub-activities. However, for ease of comparison of cases, 
the time figures are categorised as productive and non-productive times and presented in Figure 2. The first two columns show diesinking EDM and the latter two columns represents wire EDM.

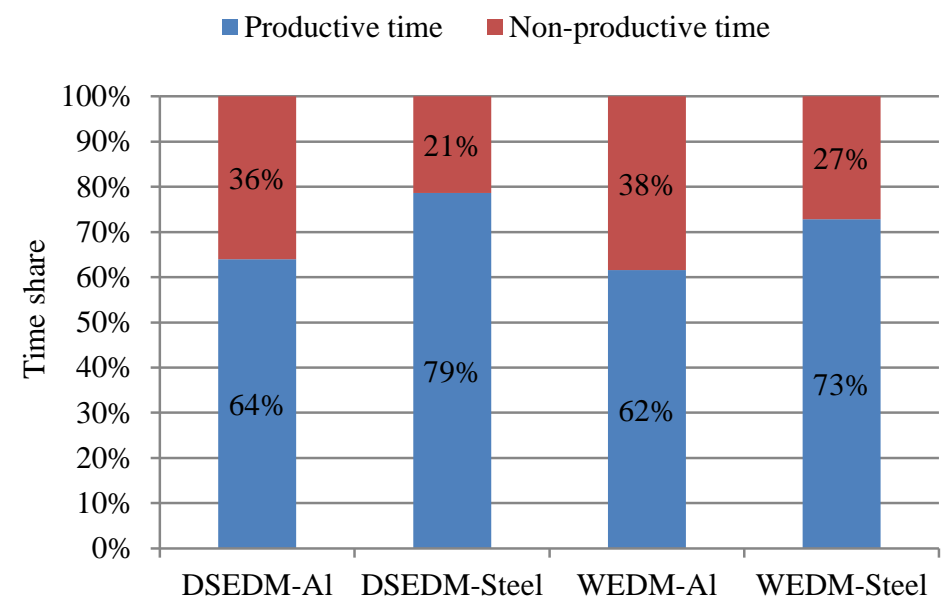

Figure 2: Time comparison of all four case studies

The actual machining time depends on job specific parameters including material type, the surface finish required and the complexity of the shape. Figure 2 is based on one hour of machining, which means the productive time value is an hour in all cases. A one hour basis is taken to ensure the simplicity of LCI calculations by apportioning resources and consumables for LCA.

The time study is not intended to identify any productivity improvement as is done when taking a traditional industrial engineering viewpoint, but instead, it is carried out to supplement the energy studies which follow. However, it can be seen from Figure 2 that $70 \%$ productive time is associated with $30 \%$ of non-productive time. Productive time or machining time depends on the machining parameters, such as discharge current, on-off time, material type, etc., which are hard to improve by process modifications. On the other hand, non-productive time can be improved with soft parameters, like operator training and more organised manufacturing management practices such as lean manufacturing. However, the improvement potential and its impact on sustainable machining are yet to be researched. Higher non-productive time is sometimes caused by unexpected events during machining, such as wire breakages during WEDM. To elaborate the excess time and comprehensive time study results, Figure 3 is presented for the instance of the Al wire cut.

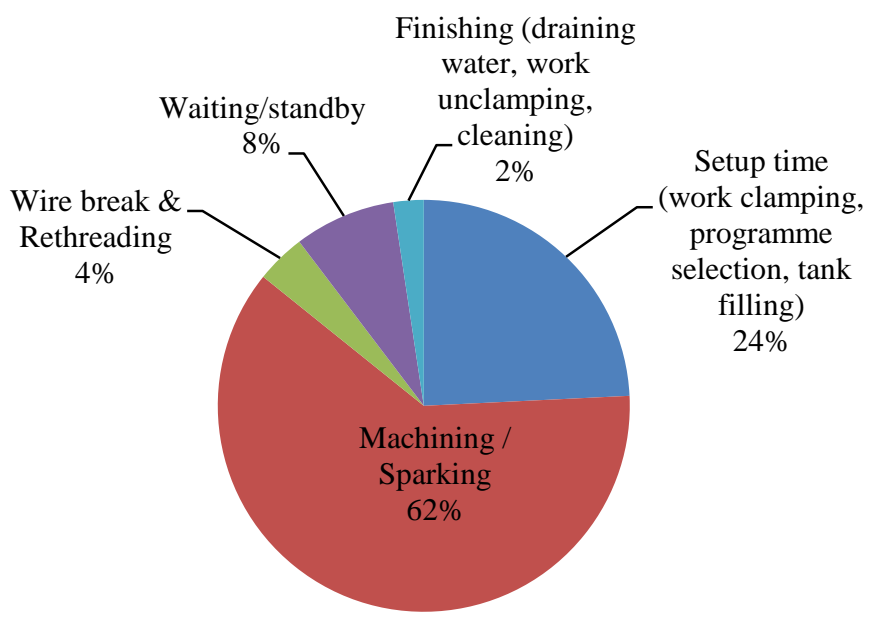

Figure 3 : Detailed time study results of $\mathrm{Al}$ wire EDM case 
Wire breakage and rethreading (automatic) time therefore accounted for $4 \%$ of the total job time. These additional factors add excess energy and resource consumption. However, the effect of wire failure is excluded for subsequent calculations of specific energy and material removal rate. The discharge qualities of $\mathrm{Al}$ are lower than those of steel, therefore there is a higher tendency for wire failures in Al wire cutting than in steel wire cutting. Figure 3 shows how the $38 \%$ of non-productive time is distributed during the $\mathrm{Al}$ wire cut case. Detailed time studies of other cases are not presented, as those are used and reflected in the energy study results which follow.

\subsection{Energy study}

The objective of the energy study is to find the electrical energy consumption per hour of machining for a given material removal rate. Figure 4 shows the specific energy consumption for each case study and the respective MRR in the secondary axis. The MRR for a given material is dependent on variety of parameters including discharge current and pulse on-off time. The MRR is calculated fully empirically using time study data and the dimension of the cut. Typical MRR rates range from about 0.1 to $10 \mathrm{~mm}^{3} \mathrm{~min}^{-1} \mathrm{~A}^{-1}$ (McGeough, 1988). However, for predictive calculations of MRR, a few theoretical methods are available. These include assessing the waste streams of EDM to calculate MRR by considering the melting point of the workpiece material (Yeo et al., 1998), a semi-empirical method (Wang and Tsai, 2001) and a dimensional analysis method (Yahya and Manning, 2004).

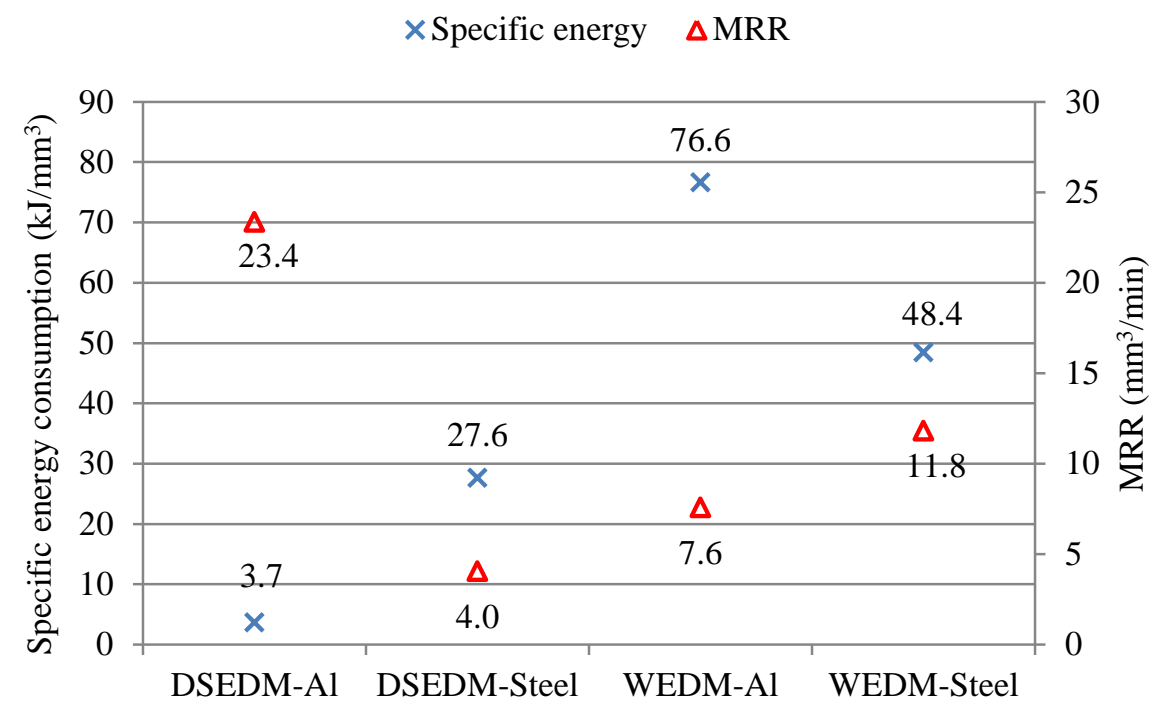

Figure 4: Resultant MRR values and specific energy values for each case

The specific energy consumptions (SEC) are calculated using the total electrical energy consumption for an hour of machining including non-productive energy consumption (Please note that in WEDM-Al case the nonproductive energy caused by wire failure is excluded to allow fair comparison). Both specific energy and MRR values are comparatively in line with the range/degrees of values presented in a prior study (Gutowski et al., 2006). The first two cases, DSEDM-Al and DSEDM-Steel, and the last two cases, WEDM-Al and WEDMSteel, are discussed pairwise for ease of comparison. In the first case, DSEDM-AL, the high recorded rate of $23.4 \mathrm{~mm}^{3} / \mathrm{min}$ can be explained by the large contact area of the electrode and the material type (aluminium). This caused the lower specific energy value of $3.7 \mathrm{~kJ} / \mathrm{mm}^{3}$. In the second case, DSEDM-Steel, the specific energy rose to over seven times more $\left(27.6 \mathrm{~kJ} / \mathrm{mm}^{3}\right)$ than the previous case and the MRR had a much lower value, of $4.0 \mathrm{~mm}^{3} / \mathrm{min}$, compared to aluminium case. A more detailed comparison is difficult as the researcher had minimal control over the machining configurations in the industrial setup used as this study's context. In the third case, WEDM-Al, the SEC value reached its highest level, of $76.6 \mathrm{~kJ} / \mathrm{mm}^{3}$ and the MRR shows a 7.6 $\mathrm{mm}^{3} / \mathrm{min}$ value which shows a slower machining rate than that of the WEDM-Steel case. 
This may be due to the higher non-productive energy associated with starting up and shutting down activities. In the last case, WEDM-steel, a slightly higher MRR of $11.8 \mathrm{~mm}^{3} / \mathrm{min}$ and a lower SEC value of $48.4 \mathrm{~kJ} / \mathrm{mm}^{3}$ was recorded in comparison to the aluminium case. In general it is expected that aluminium should be easier to cut than steel, though these results show otherwise due to process uncertainties like wire failure due to poor discharge.

Energy study of Die-sinking EDM with Al and Steel - Cases I and II

The total energy consumption during machining of aluminium alloy and tool steel (P20) are presented in Figure 5. Both studies involved discharge current of $6 \mathrm{~A}$ and single cutting mode (rough cut). The tooled steel was for a plastic mould of a fast-moving consumer product.

- Productive energy $\quad$ Non-productive energy

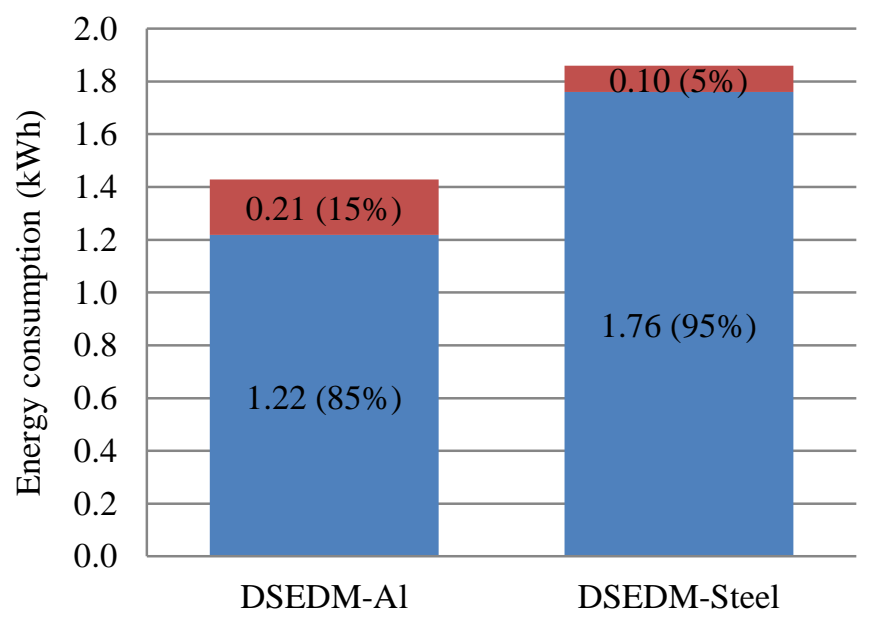

Figure 5: Energy consumption during one hour of DSEDM ${ }^{1}$

The total energy consumption is seen to be greater for steel machining than for aluminium, with a productive mode difference of $0.54 \mathrm{kWh}$. Non-productive mode consumption is almost half for steel compared to $\mathrm{Al}$, which could be due to the more efficient set up process. For LCI purposes this graph is formulated for one hour of machining and includes the non-productive activities which are essential to perform that one hour of machining. The non-productive activities are encapsulated for the machining task as they fall within the scope of unit process LCI.

Energy study of Wire EDM with Al and Steel - Cases III and IV

As for the DSEDM cases, Figure 6 compares the energy consumption levels during the Wire EDM of Al and Steel calculated for one hour of machining.

\footnotetext{
${ }^{1}$ Please note the contact areas were different for each case.
} 
- Productive energy $\quad$ Non-productive energy

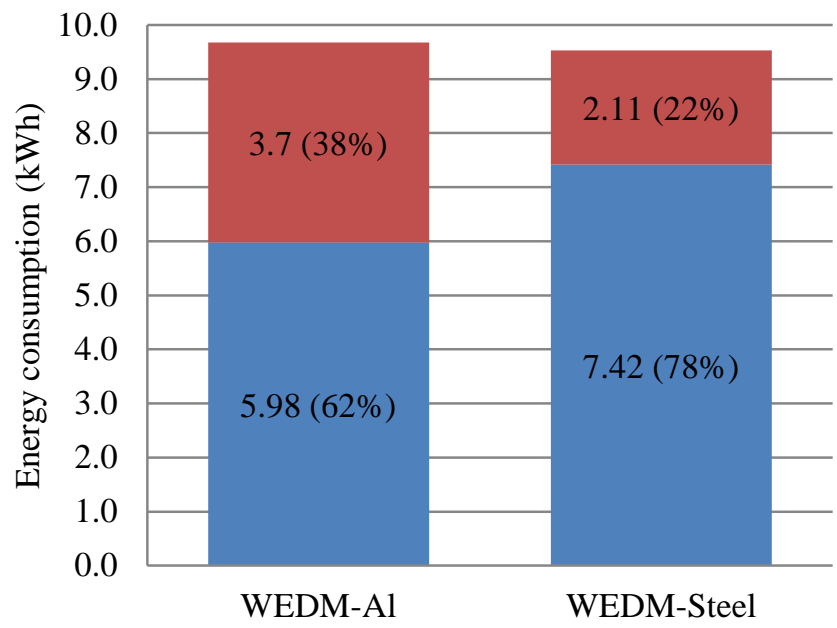

Figure 6 : Energy consumption during one hour of WEDM

Although they could be improved in terms of efficiency, non-productive activities are essential in order for the productive/machining mode to take place. Hence, it is accounted for LCI of one hour of machining. The material removal rates (MRR) for aluminium and steel during WEDM are $7.6 \mathrm{~mm}^{3} / \mathrm{min}$ and $11.8 \mathrm{~mm}^{3} / \mathrm{min}$ (Figure 4) respectively for a single mode of cut. It can be seen from Figure 6 that the total energy consumption is slightly higher for aluminium cutting than it is for steel. However, the energy consumption during productive/machining mode is lower for aluminium than for steel by $1.44 \mathrm{kWh}$. Further, energy consumption in the non-productive mode is almost half of the energy consumption in productive mode for aluminium, whereas it is only a fourth of the consumption in the productive mode for steel. It is observed that several wire breakages occurred during aluminium cutting which will make the non-productive energy consumption even higher, whereas no wire failures occurred while machining steel. This can be explained with reference to the favourable discharge qualities of steel than aluminium. A detailed study on how wire failure affects the process energy is presented in (Gamage and DeSilva, (2016) and a detailed energy study showing how different sub units contribute during each stage of machining in presented in (Gamage et al., (2016).

\subsection{Resources study}

This section summarises the resources required for each machining case. As most of the resources are reused, they are apportioned considering the total life years of each particular resource. For example, dielectric fluid is replaced every five years. The total dielectric volume is therefore apportioned into the total working hours for five years to calculate the exact consumption per hour. An identified list of resources for each case are apportioned to an hour of machining as appropriate and the results are summarised in Table 5.

Table 5: Summary of resource consumption for EDM

\begin{tabular}{|c|c|c|c|c|}
\hline Resource type & $\begin{array}{l}\text { Case I } \\
\text { DSEDM-Al }\end{array}$ & $\begin{array}{l}\text { Case II } \\
\text { DSEDM-Steel }\end{array}$ & $\begin{array}{l}\text { Case III } \\
\text { WEDM-Al }\end{array}$ & $\begin{array}{l}\text { Case III } \\
\text { WEDM-Steel }\end{array}$ \\
\hline Dielectric & $\begin{array}{l}\text { Hydrocarbon oil (Esso } \\
\text { lector }{ }^{\mathrm{TM}} 35 \text { ) } \\
\text { Flush rate of } 0.545 \mathrm{~m}^{3} / \mathrm{hr} \\
\text { Replaced every } 5 \text { years }\end{array}$ & $\begin{array}{l}\text { Hydrocarbon oil (Esso } \\
\left.\text { lector }{ }^{\mathrm{TM}} 35\right) \\
\text { Flush rate of } 0.545 \mathrm{~m}^{3} / \mathrm{hr} \\
\text { Replaced every } 5 \text { years }\end{array}$ & $\begin{array}{l}\text { Deionised water } \\
1.51 \times 10^{-3} \mathrm{~m}^{3} / \mathrm{hr} \text { approx. } \\
\text { Replaced every year }\end{array}$ & $\begin{array}{l}\text { Deionised water } \\
1.51 \times 10^{-3} \mathrm{~m}^{3} / \mathrm{hr} \text { approx. } \\
\text { Replaced every year }\end{array}$ \\
\hline Lubricant & $\begin{array}{l}\text { Hydrocarbon } \quad \text { (Mobil } \\
\text { Vectra }^{\mathrm{TM}} \text { ) }-43 \mathrm{ml} / \mathrm{hr}\end{array}$ & $\begin{array}{l}\text { Hydrocarbon } \quad \text { (Mobil } \\
\left.\text { Vectra }^{\mathrm{TM}}\right)-43 \mathrm{ml} / \mathrm{hr}\end{array}$ & $\begin{array}{l}\text { Hydrocarbon } \quad \text { (Mobil } \\
\text { Vectra }^{\mathrm{TM}} \text { ) }-43 \mathrm{ml} / \mathrm{hr}\end{array}$ & $\begin{array}{l}\text { Hydrocarbon } \\
\text { Vectra }^{\mathrm{TM}} \text { ) }-43 \mathrm{ml} / \mathrm{hr}\end{array}$ \\
\hline $\begin{array}{l}\text { Deionising resins } \\
\text { (Polystyrene beads) }\end{array}$ & N/A & N/A & $\begin{array}{l}10 \mathrm{~kg} \text { replaced twice a } \\
\text { year }\end{array}$ & $\begin{array}{l}10 \mathrm{~kg} \text { replaced twice a } \\
\text { year }\end{array}$ \\
\hline Dielectric filters & $\begin{array}{l}\text { Cartridge type oil filter } \\
(\varnothing 15 \mathrm{~cm} \times 45 \mathrm{~cm} \text { long })\end{array}$ & $\begin{array}{l}\text { Cartridge type oil filter } \\
(\varnothing 15 \mathrm{~cm} \times 45 \mathrm{~cm} \text { long })\end{array}$ & $\begin{array}{l}\text { Flush type water filters } \\
\text { Replaced after } \quad 1.5\end{array}$ & $\begin{array}{l}\text { Flush type water filters } \\
\text { Replaced after } 1.5\end{array}$ \\
\hline
\end{tabular}




\begin{tabular}{|c|c|c|c|c|c|c|}
\hline & & & $\begin{array}{l}2 \text { units - replaced twice a } \\
\text { year }\end{array}$ & $\begin{array}{l}2 \text { units - replaced twice a } \\
\text { year }\end{array}$ & $\begin{array}{l}\mathrm{kg} / \mathrm{cm}^{2} \quad \text { pressure } \\
\text { threshold is reached } \\
\text { (approx. One year) }\end{array}$ & $\begin{array}{l}\mathrm{kg} / \mathrm{cm}^{2} \text { pressure } \\
\text { threshold is reached } \\
\text { (approx. One year) }\end{array}$ \\
\hline $\begin{array}{l}\text { Cotton } \\
\text { cleaning }\end{array}$ & waste & for & $\begin{array}{l}\text { Approx. } \\
\text { time }\end{array}$ & $\begin{array}{l}\text { Approx. } 6.25 \mathrm{~g} \text { each } \\
\text { time }\end{array}$ & $\begin{array}{l}\text { Approx. } 6.25 \mathrm{~g} \text { each } \\
\text { time }\end{array}$ & $\begin{array}{l}\text { Approx. } 6.25 \mathrm{~g} \text { each } \\
\text { time }\end{array}$ \\
\hline
\end{tabular}

\subsection{Emissions study}

Materials which are emitted out of the system boundary and are not accounted for elsewhere for LCI are considered here. Emissions usually refer to gaseous or aerosols emissions. However, solid and liquid emissions are also considered here as emissions for LCI (see Table 6). During EDM, workpiece is gradually eroded with successive discharges. These small particles are flushed away with the dielectric and finally filtered out in filters. Similarly, the tool is also slightly eroded by sparks. The lost tool material (copper) is calculated using the tool wear ratio of $0.45 \%$ indicated in the technical data manual for a given material and discharge current. These filtered matters are returned to the ecosphere once dielectric filters are replaced. Therefore, both lost workpiece and tool material have to be accounted for in LCI calculations and these are summarised in Table 6.

Table 6: Summary of emissions values for one hour of EDM

\begin{tabular}{|c|c|c|c|c|}
\hline Emission type & $\begin{array}{l}\text { Case I } \\
\text { DSEDM-Al }\end{array}$ & $\begin{array}{l}\text { Case II } \\
\text { DSEDM-Steel }\end{array}$ & $\begin{array}{l}\text { Case III } \\
\text { WEDM-Al }\end{array}$ & $\begin{array}{l}\text { Case III } \\
\text { WEDM-Steel }\end{array}$ \\
\hline Workpiece material lost & $\begin{array}{l}\text { Aluminium alloy }(3003) \\
1,400.95 \mathrm{~mm}^{3}(3.82 \mathrm{~g})\end{array}$ & $\begin{array}{l}\text { Tool steel (P20/ASTM } \\
\text { A681) } \\
242.22 \mathrm{~mm}^{3}(1.90 \mathrm{~g})\end{array}$ & $\begin{array}{l}\text { Aluminium alloy (3003) } \\
454.8 \mathrm{~mm}^{3}(1.24 \mathrm{~g})\end{array}$ & $\begin{array}{l}\text { Tool steel (P20/ASTM } \\
\text { A681) } \\
709 \mathrm{~mm}^{3}(5.57 \mathrm{~g})\end{array}$ \\
\hline Tool material lost & $\begin{array}{l}\text { Copper } \\
11.77 \mathrm{~mm}^{3}\end{array}$ & $\begin{array}{l}\text { Copper } \\
1.15 \mathrm{~mm}^{3}\end{array}$ & $\begin{array}{l}\text { Used up brass wire } \\
(\varnothing 0.2 \mathrm{~mm})-111.12 \mathrm{~g}\end{array}$ & $\begin{array}{l}\text { Used up brass wire } \\
(\varnothing 0.2 \mathrm{~mm})-95.96 \mathrm{~g}\end{array}$ \\
\hline $\begin{array}{l}\text { Gaseous emissions } \\
\text { Aliphatic, BTEX, PAH }\end{array}$ & Excluded & Excluded & Excluded & Excluded \\
\hline
\end{tabular}

Unless enclosed by a dedicated emission capturing arrangement, the measurement of gaseous emissions is particularly hard. Additionally, in most industry setups, EDM machines share the same space as other machines with a common exhaust system. The discharge current is one of the main factors deciding MRR, and temperature levels near the processing zone can lead to higher emission rates. On the other hand, maintaining a certain level of dielectric over the processing point helps to dissolve, precipitate or condense emissions in dielectric before emitting them into the surrounding atmosphere. The recommended value provided by the German occupational protection agency is $40 \mathrm{~mm}$ above the emission source (Pfeiffer et al., 1995). Emissions during EDM which have a strong influence from the tool and workpiece include aliphatic compounds and metals. In contrast, volatile organic compounds (VOCs, mainly BTEX compounds) and polycyclic aromatic hydrocarbons (PAH) have no strong relationship with the tool or workpiece properties (Evertz et al., 2006). Therefore, VOCs and PAHs emissions during EDM can reasonably be used to predict emissions during EDM using petroleum based dielectrics. However, in order to generate considerable emissions, a study by Evertz et al., (2006), used high discharge currents like 32A, 64A, 128A and 192A, and a workpiece containing Ni and Cr. All four case studies in this research are conducted under a 10A discharge current and using different materials, and it is not therefore logical to use these emission figures for the impact assessment.

\subsection{Environmental impact assessment}

The data gathered from one hour of machining in each case are then used in an environmental performance analysis. The assessment refers to the Ecoinvent version 3.1 LCI database for assessment and uses the SimaPro® 8 software tool. A variety of methods can be used for impact assessment, such as Eco-indicator 99, CML 2001, EDIP 97 (Dreyer et al., 2003), and Impact 2002+ (Jolliet et al., 2003), and they are selected based on the approach, mid-point or end-point of the environmental mechanism. The assessment method used here is ReCiPe 2008, which takes into account both the midpoint and endpoint measures of the environmental mechanism, which has the advantage of expressing the impact using a single score (Goedkoop et al., 2013). 
Figure 7 shows the environmental performance of one hour of EDM at a discharge current of 6A (MRR 23.4 $\mathrm{mm}^{3} / \mathrm{min}$ ) with a copper tool and an aluminium work for the first case.

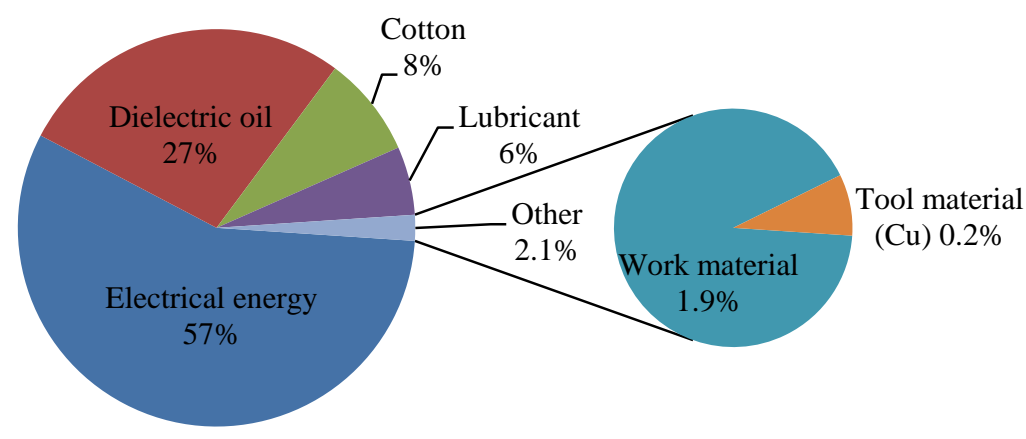

Figure 7: Environmental impact of one hour of DSEDM of Al work and Cu tool - Method: ReCiPe Endpoint (H) V1.11 / Europe ReCiPe H/A / Single score

It is evident that the main contributors are the electrical energy (57\%) and the hydrocarbon oil (27\%) used as dielectric. The total impact in absolute terms amounts to $183.9 \mathrm{mPt}$ (milli-points). The 'Point or personequivalents' used in presenting the normalised endpoint score represents the thousandth of the annual environmental load of an average European inhabitant and is expressed in units of one thousandth to better represent smaller values (Dreyer et al., 2003; Goedkoop and Spriensma, 2001). The work material lost (1.9\%) and the tool material lost $(0.2 \%)$ are the lowest impact categories. However, the impact of the dielectric filters is ignored here as the material composition is not known and could vary by machine type.

Figure 8 shows the environmental performance of one hour of diesinking EDM of P20 tool steel machined with a copper tool. The MRR is $4.04 \mathrm{~mm}^{3} / \mathrm{min}$ with a discharge current of 6A, which is the same as the DSEDM-Al case. Despite the same discharge current, significantly different MRR values can be seen, which may be due to the other operating parameters and properties of $\mathrm{Al}$ and $\mathrm{Cu}$.

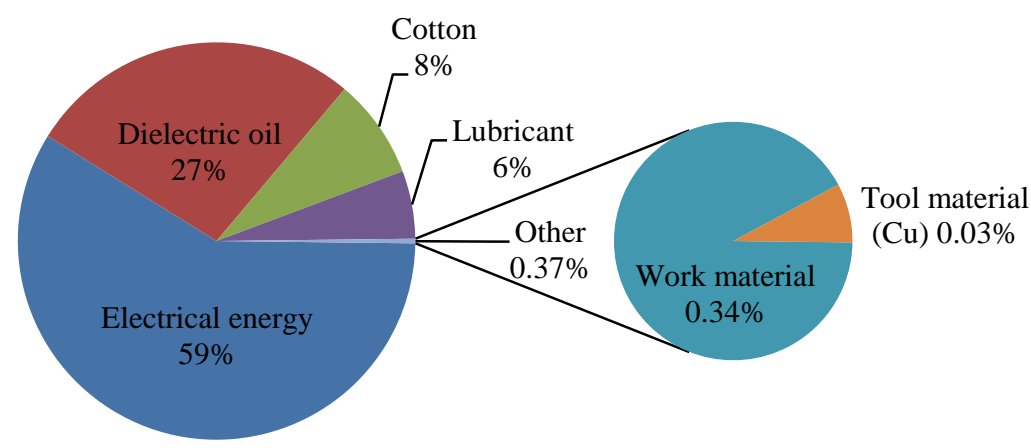

Figure 8: Environmental impact of one hour of DSEDM of Steel work and Cu tool - Method: ReCiPe Endpoint (H) V1.11 / Europe ReCiPe H/A / Single score

The absolute impact figure is $185.3 \mathrm{mPt}$, which is slightly higher than that for aluminium. Once apportioned to the one hour time scale, some resources, such as dielectric and lubricant consumption, are similar irrespective of the work and tool parameters. However, the impact figures for electrical energy, work and tool materials depend on the discharge current, productive/unproductive time, type of tool/workpiece material and other unknown parameters. From both cases it can be concluded that almost $60 \%$ of the impact is due to the electrical energy 
and $30 \%$ is due to the dielectric hydrocarbon. The remaining $10 \%$ of the impact is caused by the cleaning materials, lubrication, and the work and tool materials.

\section{Impact of Wire EDM - Cases III \& IV}

The key difference in terms of resource consumption in WEDM is the use of deionised water as the dielectric in contrast to the use of hydrocarbon oil in DSEDM. The latter has a significant impact compared to water in terms of the endpoint impact category of resource depletion. Further, the tool material used in WEDM, brass wire, is completely discarded whereas in DSEDM only the eroded volume of tool material is used for impact calculation as the remaining tool material can either be reused or recycled. The MRR for WEDM-Al is $7.6 \mathrm{~mm}^{3} / \mathrm{min}^{\text {and }}$ for WEDM-Steel it is $11.8 \mathrm{~mm}^{3} / \mathrm{min}$ with the same diameter $(0.2 \mathrm{~mm})$ of brass wire. Favourable discharge parameters such as the electrical conductivity of steel allow for higher material removal rates than aluminium under similar machining conditions. Figure 9 shows the impact assessment results for one hour of wire EDM of aluminium.

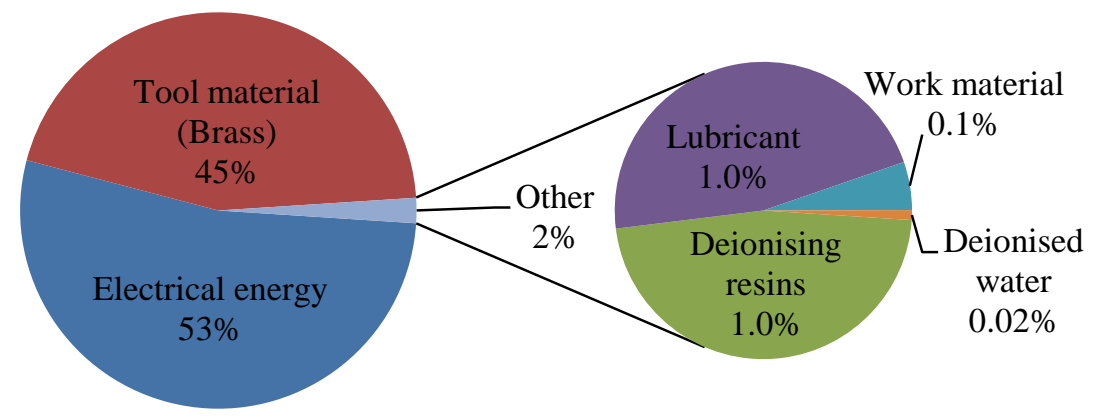

Figure 9: Environmental impact of one hour of WEDM of aluminium with brass wire - Method: ReCiPe Endpoint (H) V1.11 / Europe ReCiPe H/A / Single score

The main similarity shared by both machining types is that the main impact source is electrical energy. Dielectric fluid, on the other hand, is the second highest impact source in DSEDM but the lowest impact source in WEDM, as deionised water causes almost zero impact compared to hydrocarbon oil. Interestingly, the tool material (brass) is the second highest impact source for WEDM, whereas for DSEDM, tool material (copper) is the lowest impact source (see Figure 9 and Figure 10).

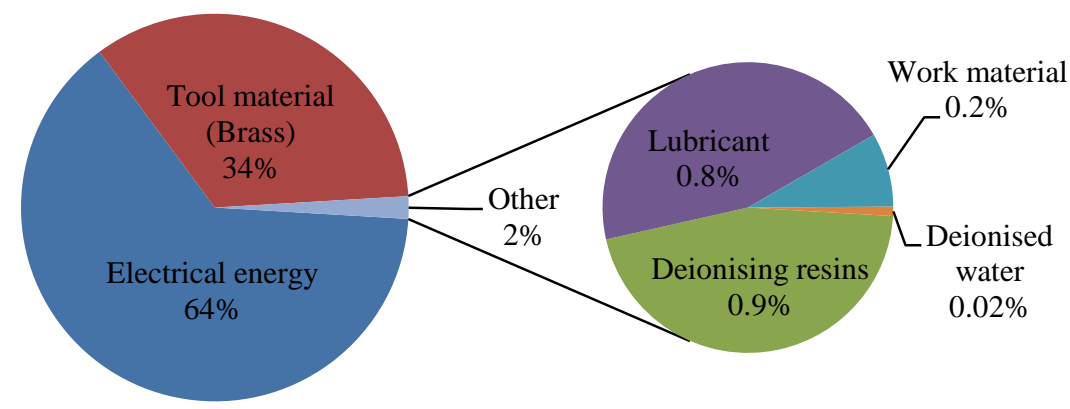

Figure 10: Environmental impact of one hour of WEDM of P20 steel with brass wire - Method: ReCiPe Endpoint (H) V1.11 / Europe ReCiPe H/A / Single score

The total absolute impact value for WEDM-Al case is 1,066 mPt, and 1,208 $\mathrm{mPt}$ for WEDM-Steel. The main observation to be made in relation to WEDM cases is that about $98 \%$ of the environmental impact has been caused by electrical energy and the wire material, with electrical energy contributing over $50 \%$ of the impact. 


\subsection{Sensitivity analysis}

It is worthwhile to find out which of the input sources influence the final outcome most, and how significant they are when compared to each other. Measurement limitations, the capabilities of the equipment and the methods used may all affect the absolute LCI values. A sensitivity analysis is therefore carried out to improve the confidence of the results obtained. It will further help to moderate the case-specific parameters in order to build a more generalised idea of EDM process level impacts. Thus, the sensitivity analysis is carried out by altering significant parameters to discover the changes in total environmental impact figures. As per Figure 7 and Figure 8, for DSEDM, electrical energy and dielectric are the most significant impact sources and both are functions of time. Hence, changing electrical energy and dielectric imply a change in machining time as well. Therefore, the influence on total environmental impact from electrical energy and dielectric are used for the diesinking cases.

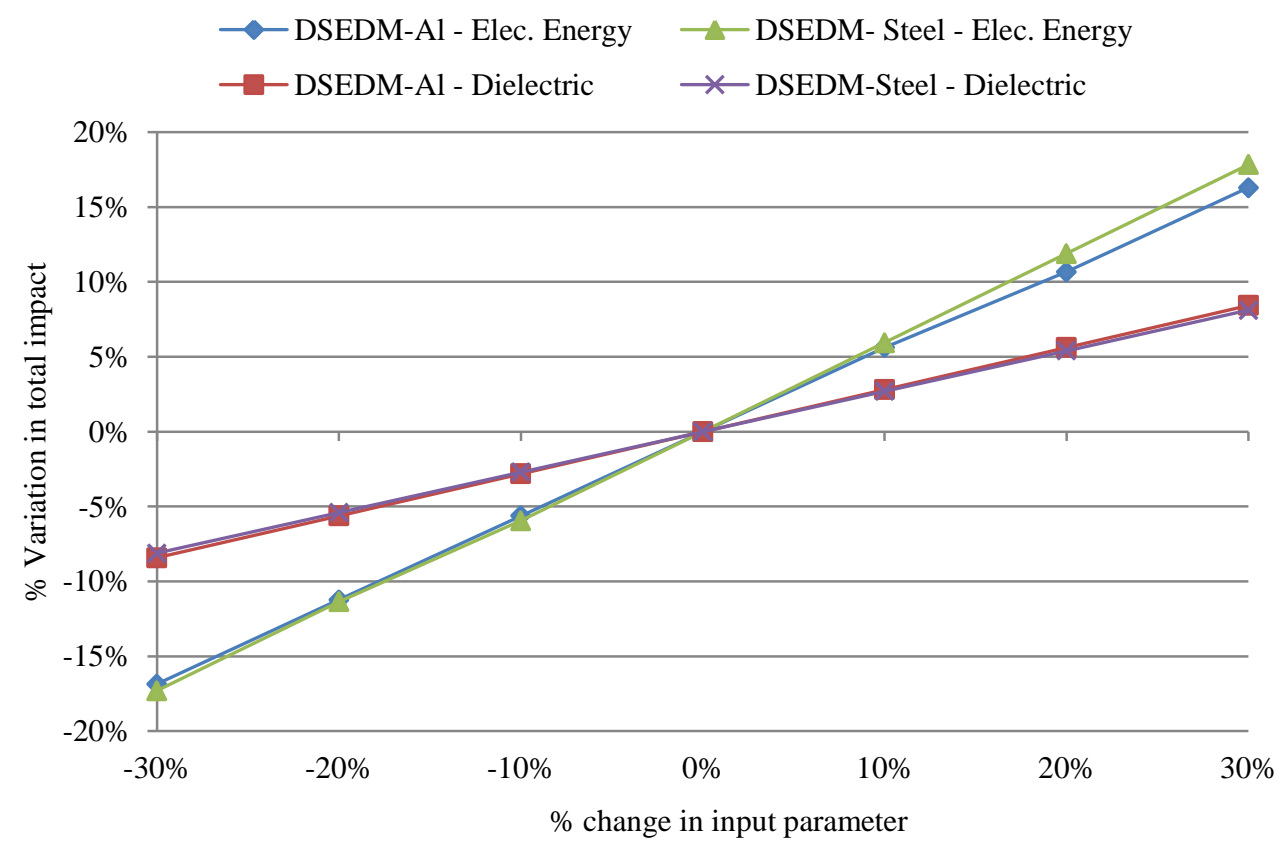

Figure 11: Sensitivity of electrical energy and dielectric on total impact during diesinking EDM

Input parameters are changed in $10 \%$ steps both ways and the corresponding impact values under ReCiPe Endpoint (H) V1.11 / Europe ReCiPe H/A / single score method are plotted as shown in Figure 11. The alterations were made while keeping the other parameters constant as the interdependencies among parameters are not known. It can be seen from the graph that both parameters, energy and dielectric, have a strong positive correlation to the total environmental impact. Electrical energy seems more sensitive to the total impact as the gradients are higher than the gradients of dielectric lines. Further, case specific or material specific variation cannot be seen from the graph. 


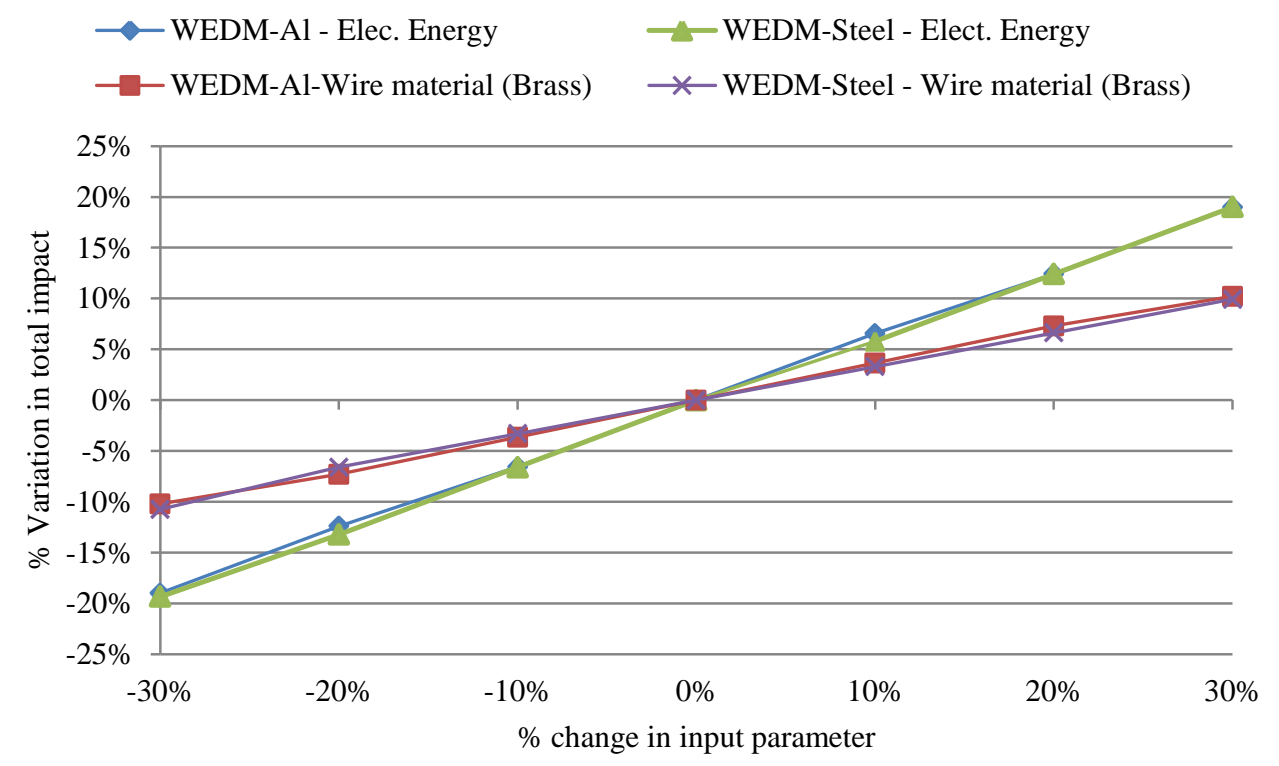

Figure 12. Sensitivity of electrical energy and wire material on total impact during wire EDM

In the WEDM process (cases III and IV), the second most influential input parameter is the wire material (brass), unlike dielectric in DSEDM. The most sensitive parameter is again electrical energy, with almost twice the influence of wire material in the WEDM-Steel case. A direct proportionality can be seen in the total impact value and input variables in the graphs in both Figure 11 and Figure 12. The electrical energy consumption of WEDM-Steel case is more sensitive to the total environmental impact (with a gradient of 0.064) than that of WEDM-Al case (slightly lower slope of 0.054). All four parameters have a strong positive correlation with a $\mathrm{R}^{2}$ value of 0.999. In both WEDM and DSEDM cases, the electrical energy during steel machining is more sensitive to the impact figure than machining of aluminium.

\section{Conclusions}

Four case studies of DSEDM and WEDM, with aluminium alloy 3003 and tool steel AISI P20, have been investigated in this study. The unit process LCI data of unconventional machining have been ascertained through time, energy, resources and emissions studies for each case. Despite some limitations relating to acquiring airborne emissions data, all other input and output reference flows were traced and analysed. It is shown that a considerable amount of energy consumption occurs during the non-productive stages of machining which is responsible for extended environmental impacts. The results show that the main source of impact is electrical energy in all four cases, which is responsible for approximately $60 \%$ of the total impact in each case. However, the second highest impact source is dielectric oil (hydrocarbon) for DSEDM whereas for WEDM, it is the wire material (brass). This reflects the significance of the 'Resource availability' in comparison to other endpoint categories, Damages to human health and Ecosystem diversity.

In view of the Pareto approach, the most significant impact source, which is electrical energy, can be controlled through appropriate machine tool design and also by using sensible operating procedures. A typical EDM machine is automated to a great extent, and is programmed to operate each sub unit based on manufacturer specific algorithms. All the energy consuming sub units, such as pumps and chillers, have room for optimisation for better energy performance apart from the focus quality of cut.

The introduction of alternative types of dielectric media with lower impact to replace hydrocarbon oil would represent another dimension of research. Operational level improvements can also be suggested to keep energy and resource consumption to a minimum level. As can be seen from the present results, keeping machines in standby mode uses a considerable amount of energy. This is mainly due to chillers and pumps triggering to keep the dielectric at a set temperature. Improved production planning and awareness are required to better utilise the 
machines in productive mode otherwise, an OFF mode could mean higher savings potential in energy consumption and, thus, could reduce environmental impact.

Further research on process level environmental impact assessment of EDM with difference parameters is underway. An increasing concern regarding subtractive processes is the fact that only a small fraction of purchased material ends up in the final product, the rest being wasted during machining. Manufacturers cannot afford to lose a considerable amount of material during machining, and the waste of material also has an adverse impact on their environmental footprint. As EDM is being used for machining high cost Titanium and Nickel based super alloys, this study can be further developed as a cost analogue for such industries. Another area of possible research would be investigation of the possible re-use of the otherwise wasted material using low energy intensive processes.

\section{Acknowledgements}

The authors would like to extend their sincere gratitude to industry partners (Pascoe Engineering, UK, and Die and Mould Facilitation and Development Centre, Sri Lanka) for facilitating data collection and knowledge sharing. Further, they would also like to acknowledge Glasgow Caledonian University, UK, for funding this study through a PhD research grant, and the University of Moratuwa, Sri Lanka, for its continued support.

\section{References}

Aalco, 2015. Aluminium Alloy - Commercial Alloy - 3003 “0” Sheet [WWW Document]. URL http://www.aalco.co.uk/datasheets/Aluminium-Alloy-3003-0-Sheet_59.ashx

ASTM Standard B209, 2014. Standard Specification for Aluminum and Aluminum-Alloy Sheet and Plate. ASTM International, West Conshohocken, PA, 2014, DOI: 10.1520/B0209-14, www.astm.org.

British Standards Institution, 2013. BS EN 573-3:2013: Aluminium and aluminium alloys. Chemical composition and form of wrought products. Chemical composition and form of products. British Standards Institution, London.

Dahmus, J.B., Gutowski, T.G., 2004. An environmental analysis of machining, in: ASME 2004 International Mechanical Engineering Congress and Exposition. American Society of Mechanical Engineers, pp. 643-652.

Devoldere, T., Dewulf, W., Deprez, W., Duflou, J.R., 2008. Energy Related Life Cycle Impact and Cost Reduction Opportunities in Machine Design: The Laser Cutting Case. LCE 2008 15th CIRP Int. Conf. Life Cycle Eng. Conf. Proc. 412.

Dreyer, L.C., Niemann, A.L., Hauschild, M.Z., 2003. Comparison of Three Different LCIA Methods: EDIP97, CML2001 and Eco-indicator 99. Int. J. Life Cycle Assess. 8, 191-200. doi:10.1007/BF02978471

Duflou, J.R., Kellens, K., Dewulf, W., 2011. Unit process impact assessment for discrete part manufacturing: A state of the art. CIRP J. Manuf. Sci. Technol. 4, 129-135. doi:10.1016/j.cirpj.2011.01.008

Duflou, J.R., Sutherland, J.W., Dornfeld, D., Herrmann, C., Jeswiet, J., Kara, S., Hauschild, M., Kellens, K., 2012. Towards energy and resource efficient manufacturing: A processes and systems approach. CIRP Ann. - Manuf. Technol. 61, 587-609. doi:10.1016/j.cirp.2012.05.002

Ecoinvent centre, 2015. Ecoinvent centre [WWW Document]. Ecoinvent Database. URL http://www.ecoinvent.org/ (accessed 3.8.15).

Eurostat, 2014. Energy, transport and environment indicators, 2014th ed. Luxembourg: Publications Office of the European Union, Luxembourg.

Evertz, S., Dott, W., Eisentraeger, A., 2006. Electrical discharge machining: Occupational hygienic characterization using emission-based monitoring. Int. J. Hyg. Environ. Health 209, 423-434. doi:10.1016/j.ijheh.2006.04.005

Fratila, D., 2013. Sustainable Manufacturing Through Environmentally-Friendly Machining, in: Davim, J.P. (Ed.), Green Manufacturing Processes and Systems, Materials Forming, Machining and Tribology. Springer Berlin Heidelberg, pp. 1-21.

Gamage, J.R., DeSilva, A.K.M., 2016. Effect of Wire Breakage on the Process Energy Utilisation of EDM. Procedia CIRP, 18th CIRP Conference on Electro Physical and Chemical Machining (ISEM XVIII) 42, 586-590. doi:10.1016/j.procir.2016.02.264

Gamage, J.R., DeSilva, A.K.M., 2015. Assessment of Research Needs for Sustainability of Unconventional Machining Processes. Procedia CIRP, 12th Global Conference on Sustainable Manufacturing Emerging Potentials 26, 385-390. doi:10.1016/j.procir.2014.07.096 
Gamage, J.R., DeSilva, A.K.M., Harrison, C., Harrison, D., 2016. Ascertaining Life Cycle Inventory Data for Electrical Discharge Machining. Procedia CIRP, Research and Innovation in Manufacturing: Key Enabling Technologies for the Factories of the Future - Proceedings of the 48th CIRP Conference on Manufacturing Systems 41, 908-913. doi:10.1016/j.procir.2015.12.091

Ginting, Y.R., Boswell, B., Biswas, W., Islam, N., 2015. Advancing Environmentally Conscious Machining. Procedia CIRP, 12th Global Conference on Sustainable Manufacturing - Emerging Potentials 26, 391396. doi:10.1016/j.procir.2014.07.087

Goedkoop, M., Heijungs, R., Huijbrets, M., De Schryver, A., Struijs, J., Van Zelm, R., 2013. ReCiPe 2008 (No. 1.08), A life cycle impact assessment method which comprises harmonised category indicators at the midpoint and the endpoint level. PRé Consultants, CML- University of Leiden, RUN - Radboud University Nijmegen Netherlands - RIVM, Bilthoven, Netherland.

Goedkoop, M., Spriensma, R., 2001. The Eco-indicator99: a damage oriented method for life cycle impact assessment: methodology report.

Gutowski, T., Dahmus, J., Thiriez, A., 2006. Electrical energy requirements for manufacturing processes, in: 13th CIRP International Conference on Life Cycle Engineering, Leuven, Belgium. pp. 560-564.

Gutowski, T.G., Allwood, J.M., Herrmann, C., Sahni, S., 2013. A Global Assessment of Manufacturing: Economic Development, Energy Use, Carbon Emissions, and the Potential for Energy Efficiency and Materials Recycling. Annu. Rev. Environ. Resour. 38, 81-106. doi:10.1146/annurev-environ-041112110510

International Organisation for Standardisation, 2006. Environmental Management: Life Cycle Assessment; Requirements and Guidelines (ISO 14044:2006). ISO.

Jolliet, O., Margni, M., Charles, R., Humbert, S., Payet, J., Rebitzer, G., Rosenbaum, R., 2003. IMPACT 2002+: A new life cycle impact assessment methodology. Int. J. Life Cycle Assess. 8, 324-330. doi:10.1007/BF02978505

Kara, S., Bogdanski, G., Li, W., 2011. Electricity Metering and Monitoring in Manufacturing Systems, in: Hesselbach, J., Herrmann, C. (Eds.), Glocalized Solutions for Sustainability in Manufacturing. Springer Berlin Heidelberg, pp. 1-10.

Kellens, K., Dewulf, W., Overcash, M., Hauschild, M.Z., Duflou, J.R., 2011a. Methodology for systematic analysis and improvement of manufacturing unit process life-cycle inventory (UPLCI) - CO2PE! initiative (cooperative effort on process emissions in manufacturing). Part 1: Methodology description. Int. J. Life Cycle Assess. 17, 69-78. doi:10.1007/s11367-011-0340-4

Kellens, K., Renaldi, Dewulf, W., Duflou, J.R., 2011b. Preliminary Environmental Assessment of Electrical Discharge Machining, in: Hesselbach, J., Herrmann, C. (Eds.), Glocalized Solutions for Sustainability in Manufacturing. Springer Berlin Heidelberg, pp. 377-382.

Leão, F.N., Pashby, I.R., 2004. A review on the use of environmentally-friendly dielectric fluids in electrical discharge machining. J. Mater. Process. Technol. 149, 341-346. doi:10.1016/j.jmatprotec.2003.10.043

Li, W., Kara, S., 2015. Characterising Energy Efficiency of Electrical Discharge Machining (EDM) Processes. Procedia CIRP, The 22nd CIRP Conference on Life Cycle Engineering 29, 263-268. doi:10.1016/j.procir.2015.01.039

Maher, I., Sarhan, A.A.D., Barzani, M.M., Hamdi, M., 2015. Increasing the productivity of the wire-cut electrical discharge machine associated with sustainable production. J. Clean. Prod. doi:10.1016/j.jclepro.2015.06.047

Matweb, 2015. AISI Type P20 Mold Steel (UNS T51620) [WWW Document]. URL http://www.matweb.com/search/datasheet.aspx?matguid=2957f352a2e84857a9c41d2f31d063ec\&ckck $=1($ accessed 9.25.15).

Maynard, H.B., Zandin, K.B., 2001. Maynard's industrial engineering handbook, 5th ed. ed, McGraw-Hill standard handbooks. McGraw-Hill, New York.

McGeough, J.A., 1988. Advanced Methods of Machining. Chapmen and Hall, London.

Munoz, A.A., Sheng, P., 1995. An analytical approach for determining the environmental impact of machining processes. J. Mater. Process. Technol. 53, 736-758.

Pfeiffer, W., Schenk, C., Stockmann, R., Willert, G., 1995. Hazardous substances in electrical discharge machining (EDM) - BIA Report 9/95. Augustin.

Sivapirakasam, S.P., Mathew, J., Surianarayanan, M., 2011. Constituent analysis of aerosol generated from die sinking electrical discharge machining process. Process Saf. Environ. Prot. 89, 141-150. doi:10.1016/j.psep.2010.10.003

Tan, X.C., Liu, F., Cao, H.J., Zhang, H., 2002. A decision-making framework model of cutting fluid selection for green manufacturing and a case study. J. Mater. Process. Technol., The 10th International Manufacturing Conference in China (IMCC 2002) 129, 467-470. doi:10.1016/S0924-0136(02)00614-3

USEIA, 2013. International Energy Outlook 2013. U.S. Energy Information Administration, U.S. Department of Energy-Washington. 
Wang, P.-J., Tsai, K.-M., 2001. Semi-empirical model on work removal and tool wear in electrical discharge machining. J. Mater. Process. Technol. 114, 1-17. doi:10.1016/S0924-0136(01)00733-6

World Steel Association, 2014. WORLD STEEL IN FIGURES 2014. World Steel Association, Belgium.

Yahya, A., Manning, C.D., 2004. Determination of material removal rate of an electro-discharge machine using dimensional analysis. J. Phys. Appl. Phys. 37, 1467. doi:10.1088/0022-3727/37/10/008

Yeo, S.H., Tan, H.C., New, A.K., 1998. Assessment of waste streams in electric-discharge machining for environmental impact analysis. Proc. Inst. Mech. Eng. Part B J. Eng. Manuf. 212, 393-401. doi:10.1243/0954405981515996 